\title{
FindZebra - the search engine for difficult medical cases
}

\author{
Ole Winther ${ }^{1 *}$, Dan Svenstrup ${ }^{1}$, Philip P Henningsen ${ }^{1}$, Róbert Kristiásson ${ }^{1}$, Henrik L Jørgensen² \\ From 7th European Conference on Rare Diseases and Orphan Products (ECRD 2014)
}

Physicians as well as laypeople use both general purpose and specialised web-based search tools when confronted with medical questions. FindZebra.com is a tool for generating hypotheses about rare disease diagnosis. It uses freely available high quality curated information on rare diseases and open source information retrieval software (Apache Lucene Solr) tailored to the problem. FindZebra is intended primarily for physicians and other professionals concerned with diagnosis of rare diseases. Our benchmarking against several search tools (Google search, PubMed and http://omim.org) shows that FindZebra has higher performance in retrieving the correct diagnosis when queried with symptoms [1,2]. Our findings indicate that the ranking algorithm used is the most important factor for the success.

\footnotetext{
Authors' details

'Department for Applied Mathematics and Computer Science, Technical University of Denmark (DTU), 2800 Lyngby, Denmark. ${ }^{2}$ Copenhagen University Hospital, Department of Clinical Biochemistry, Bispebjerg Hospital, Copenhagen, Denmark.
}

Published: 11 November 2014

\section{References}

1. Dragusin Radu, Petcu Paula, Lioma Christina, Larsen Birger, Jørgensen Henrik L, Cox Ingemar, Hansen Lars K, Ingwersen Peter, Winther Ole: FindZebra: a Search Engine for Rare Diseases. International Journal of Medical Informatics, IJMI 2013.

2. Dragusin Radu, Petcu Paula, Lioma Christina, Larsen Birger, Jørgensen Henrik L, Cox Ingemar, Hansen Lars K, Ingwersen Peter, Winther Ole: Specialised tools are needed when searching the web for rare disease diagnoses. Rare Diseases 2013.

doi:10.1186/1750-1172-9-S1-05

Cite this article as: Winther et al:: FindZebra - the search engine for difficult medical cases. Orphanet Journal of Rare Diseases 2014 9(Suppl 1):05.

\footnotetext{
* Correspondence: olwi@dtu.dk

'Department for Applied Mathematics and Computer Science, Technical University of Denmark (DTU), 2800 Lyngby, Denmark

Full list of author information is available at the end of the article
}

Submit your next manuscript to BioMed Central and take full advantage of:

- Convenient online submission

- Thorough peer review

- No space constraints or color figure charges

- Immediate publication on acceptance

- Inclusion in PubMed, CAS, Scopus and Google Scholar

- Research which is freely available for redistribution 